\title{
Y-V Oncoplastic Wound Repair of Mastectomy Dog-Ear Deformity
}

\section{Mark Gittleman, MD}

Coordinated Health-Breast Care Specialists, Allentown, PA 18104

ABSTRACT The video demonstrates the surgical technique for correcting dog-ear deformity resulting from a mastectomy wound. This technique is applicable for both medial and lateral deformities.

Electronic supplementary material The online version of this article (doi:10.1245/s10434-012-2526-9) contains supplementary material, which is available to authorized users.

(C) Society of Surgical Oncology 2012

First Received: 20 May 2012;

Published Online: 31 July 2012

M. Gittleman, MD

e-mail: gittleman@aol.com 